\title{
Isolation of whiskers from natural sources and their dispersed in a non-aqueous medium
}

\author{
Mauro Vestena ${ }^{1,2 *}$, Idejan Padilha Gross ${ }^{1}$, Carmen Maria Olivera Muller ${ }^{3}$ and Alfredo Tibúrcio Nunes Pires ${ }^{1}$ \\ ${ }^{1}$ Polymeric Materials Research Group - POLIMAT, Chemistry Department, \\ Universidade Federal Santa Catarina - UFSC, Florianópolis, SC, Brazil \\ ${ }^{2}$ Chemistry Academic Department, Universidade Tecnológica Federal do Paraná - UTFPR, \\ Campus Pato Branco, Pato Branco, PR, Brazil \\ ${ }^{3}$ Department of Food Science and Technology, Universidade Federal Santa Catarina - UFSC, \\ Florianópolis, SC, Brazil \\ *mauro@utfpr.edu.br
}

\begin{abstract}
Whiskers have been used as a nanomaterial dispersed in polymer matrices to modify the microscopic and macroscopic properties of the polymer. These nanomaterials can be isolated from cellulose, one of the most abundant natural renewable sources of biodegradable polymer. In this study, whiskers were isolated from sugarcane bagasse and corn cob straw fibers. Initially, the cellulose fiber was treated through an alkaline/oxidative process followed by acid hydrolysis. Dimethylformamide and dimethyl sulfoxide were used to replace the aqueous medium for the dispersion of the whiskers. For the solvent exchange, dimethylformamide or dimethyl sulfoxide was added to the aqueous dispersion and the water was then removed by fractional distillation. FTIR, TGA, XRD, TEM, Zeta and DLS techniques were used to evaluate the efficiency of the isolation process as well as the morphology and dimensions of the whiskers. The dimensions of the whiskers are comparable with values reported in the literature, maintaining the uniformity and homogeneity in both aqueous and non-aqueous solvents.
\end{abstract}

Keywords: whiskers, cellulose bleaching, agricultural waste.

\section{Introduction}

Agricultural production has expanded in recent years and the lignocellulosic byproducts generated have great potential for exploitation as new raw materials. Agricultural byproducts, such as sugarcane bagasse (SCB) and corn cob straw (CCS), are residues produced on a large scale which, after treatment, can be added to a polymeric matrix in order to alter the physicochemical characteristics of the nanocomposites. Lignocellulosic materials consist mainly of cellulose, hemicellulose and lignin, the contents of which vary depending on the raw material and the physiological characteristics of the plant. SCB is comprised of 42 to $46 \%$ cellulose, 21 to $28 \%$ lignin and 27 to $29 \%$ of hemicellulose ${ }^{[1-3]}$. On the other hand, CCS contains 42 to $44 \%$ cellulose, 22 to $28 \%$ lignin and 27 to $28 \%$ hemicellulose ${ }^{[4-6]}$. Minor amounts of other polysaccharides (found in the cell walls) and minerals may also be present in these raw materials.

Cellulose is an abundant biopolymer which is biodegradable and renewable and it can be obtained in an environmentally sustainable manner. It has a microfibrillar structure composed of $\beta$-1,4-linked anhydro-D-glucose $\left(\mathrm{C}_{6} \mathrm{H}_{10} \mathrm{O}_{5}\right)$ units, and the repeat segment is a dimer of glucose, known as cellobiose. The spatial conformation and arrangement associated with intra- and intermolecular hydrogen bonds lead to the rigid characteristics of cellulose $\mathrm{e}^{[7,8]}$. Six interconvertible cellulose polymorphs, namely I, II, III ${ }_{1}, \mathrm{III}_{2}, \mathrm{IV}_{1}$ and $\mathrm{IV}_{2}$ have been identified, each with its particular set of network parameter characteristics of unit cells, type I being referred to as native cellulose $^{[7]}$. In order to isolate the cellulose from lignocellulosic plant materials, the non-cellulosic components (hemicellulose, lignin, etc.) need to be removed from the fiber through a process known as bleaching. Different treatments have been applied in the bleaching of natural fibers, such as the use of an alkali, followed by an oxidizing/alkaline environment with the use of an oxidant based on chlorinated compounds ${ }^{[9,10]}$. Studies have been conducted using oxidants which generate very low levels of waste, such as hydrogen peroxide, thereby reducing the environmental impact ${ }^{[1,11]}$. Rosa et al. ${ }^{[12]}$ has isolated cellulose from rice husk by cellulose extraction in two-step chlorine-free bleaching processes. Other processes are performed without the alkali treatment step, using systems such as nitric/acetic acid ${ }^{[11]}$ and peracetic acid ${ }^{[13]}$ and mixtures of hydrogen peroxide with manganese(II) sulfate and zinc oxide or manganese(II) sulfate and titanium dioxide $^{[14]}$. In the bleaching process the control variables, such as temperature, time and concentration of reagents, play an extremely important role.

After bleaching, the cellulose isolated by mechanical, chemical or enzymatic treatment can result in microcrystalline cellulose, microfibrillated cellulose or whiskers. The microfibrils which make up the cellulose fiber consist of amorphous and crystalline domains and their acid hydrolysis allows the isolation of the crystalline domains, denoted as whiskers or cellulose nanocrystals, due to the dimensional characteristics of the material. The aspect ratio of the whiskers is dependent on the variables involved in the process used to isolate the whiskers, such as the raw material, temperature, reaction 
time, reagent concentration and reagent/raw materials ratio. Habibi et al. ${ }^{[7]}$ and Moon et al. ${ }^{[15]}$ reported that whiskers have an acicular shape and length/diameter ratio of 10 to 30 , with lengths of 35 to $500 \mathrm{~nm}$ and a diameter of 3 to $15 \mathrm{~nm}$, depending on the raw material and treatment used to isolate the whiskers.

The large surface area and crystallinity of the whiskers make these promising materials for incorporation into polymeric matrixes, where they increase the mechanical strength and modify the gas barrier properties ${ }^{[7,15-17]}$. On the other hand, the whiskers can be dispersed homogeneously in polymers which are soluble in aqueous solution due to their hydrophilic surface ${ }^{[18]}$. However, this restricts their use in the matrices of hydrophobic polymers due to difficulties related to their dispersion in these systems. Studies have been directed toward obtaining an adequate dispersion of whiskers in hydrophobic matrices, using approaches such as the addition of anionic surfactants or tert-butanol to the dispersing medium ${ }^{[19]}$, the use of a cationic surfactant ${ }^{[20]}$, the use of partially hydrolyzed poly(vinyl alcohol) $)^{[21]}$, surface functionalization of the whiskers ${ }^{[22-24]}$, the use of lyophilization and redispersion in a non-aqueous solvent. Of these proposed methods, the redispersion of the whiskers in non-aqueous solvents has proved to be a promising technique which allows homogeneous dispersion in hydrophobic polymers, it being necessary to assess the process conditions in relation to the polymer matrix. Yu et al. ${ }^{[25]}$ isolated whiskers in an aqueous medium and then replaced the water with acetone and subsequently replaced the acetone with chloroform in several successive centrifugation steps and finally the whiskers were incorporated into the poly(3-hydroxybutyrateco-3-hydroxyvalerate) matrix. Pracella et al. ${ }^{[26]}$ used an analogous procedure for the solvent exchange of the whiskers suspension and subsequent incorporation of the whiskers into poly(lactic acid).

The whiskers yield from the isolation process, as well as the whiskers suspension in non-aqueous solvents and subsequent incorporation into the hydrophobic polymer matrix, are dependent on the characteristics of the raw material, the bleaching process and the procedure used for the isolation of the whiskers, in addition to the characteristics of the solvent used in the suspension and the polymer matrix employed to produce the nanocomposite.

In this context, the aim of this study was to evaluate the processes used for the isolation of whiskers from sugarcane bagasse and corn cob straw, to promote the exchange of the whiskers dispersing medium and keep the whiskers homogeneously dispersed in non-aqueous solvents to facilitate the obtainment of a nanocomposite polymeric matrix containing whiskers.

\section{Materials and Methods}

\subsection{Materials}

The sugarcane bagasse (SCB) was provided by regional ethanol producers (São Paulo, SP Brazil) and the corn cob straw (CCS) by regional organic producers (Pato Branco, PR Brazil). Poly(lactic acid) (Code 3251D) was purchased from NatureWorks, Cargill (Minnetonka, MN, USA). Sulfuric acid, sodium hydroxide and hydrogen peroxide were purchased from Lafan Química Fina, and dimethylformamide (DMF) and dimethyl sulfoxide (DMSO) were supplied by Nuclear (Brazil). Cellulose was purchased from Merck and lignin obtained by isolation from the raw materials (SCB and CCS) according to regulation TAPPI T222 om- $88^{[24]}$. All of the chemical reagents were used without further purification.

\subsection{Bleaching of fibers from raw materials}

The SCB and CCS raw materials were washed with distilled water, dried and milled and then passed through a 30-mesh sieve. In the next step, the fibers were dried in an oven with air circulation at $105{ }^{\circ} \mathrm{C}$ for $4 \mathrm{~h}$ prior to the bleaching process. For the bleaching process, three different procedures were applied: $(i)$ treatment with $\mathrm{NaOH}$ aqueous solution; (ii) treatment with $\mathrm{H}_{2} \mathrm{O}_{2}$; and (iii) treatment with $\mathrm{Ca}(\mathrm{ClO})_{2}$ aqueous solution.

(i) Treatment with $\mathrm{NaOH}$ aqueous solution - The fibers were maintained in a $5 \%$ aqueous solution of $\mathrm{NaOH}$ (1:20 w/v fiber/solution) at $85{ }^{\circ} \mathrm{C}$ for $90 \mathrm{~min}$, under mechanical stirring. In the next step, the dispersion was filtered and the fibers washed until neutral $\mathrm{pH}$ and dried at $105^{\circ} \mathrm{C}$ for $4 \mathrm{~h}$. The fibers obtained through this treatment are denoted as $\mathrm{SCB} / \mathrm{NaOH}$ or $\mathrm{CCS} / \mathrm{NaOH}$, according to the raw material.

(ii) Treatment with $\mathrm{H}_{2} \mathrm{O}_{2}$ - The fibers subjected to treatment (i) were then maintained in an aqueous solution of $5 \%$ $\mathrm{NaOH}$ and $11 \% \mathrm{H}_{2} \mathrm{O}_{2}(1: 20 \mathrm{w} / \mathrm{v})$ at $55^{\circ} \mathrm{C}$ for $90 \mathrm{~min}$ and the dispersion was filtered. The fibers were then washed with distilled water until neutral $\mathrm{pH}$ and dried at $105^{\circ} \mathrm{C}$ in an oven with air circulation for $4 \mathrm{~h}$. These treated fibers were denoted by $\mathrm{SCB} / \mathrm{H}_{2} \mathrm{O}_{2}$ or $\mathrm{CCS} / \mathrm{H}_{2} \mathrm{O}_{2}$, according to the raw material.

(iii)Treatment with $\mathrm{Ca}(\mathrm{ClO})_{2}$, aqueous solution - Fibers subjected to treatment $(i)$ were maintained in an aqueous solution of $2.5 \% \mathrm{Ca}(\mathrm{ClO})_{2}$ and $5 \% \mathrm{NaOH}(w / v)$, at $45^{\circ} \mathrm{C}$ for $240 \mathrm{~min}$ and the dispersion was filtered. The fibers were then washed until neutral $\mathrm{pH}$ and dried at $105{ }^{\circ} \mathrm{C}$ for $4 \mathrm{~h}$. These treated fibers were denoted by $\mathrm{SCB} / \mathrm{Ca}(\mathrm{ClO})_{2}$ or $\mathrm{CCS} / \mathrm{Ca}(\mathrm{ClO})_{2}$, according to the starting raw material.

\subsection{Characterization of raw materials and bleached fibers}

To evaluate the effect of bleaching on the composition and crystallinity of the lignocellulosic materials, SCB and CCS samples before and after the bleaching processes were characterized by Fourier transformed infrared spectroscopy (FTIR), thermogravimetry analysis (TG) and X-ray diffraction (XRD). The cellulose, lignin and hemicellulose contents of the untreated SCB and CCS were determined in accordance with the respective recommendations of the Technical Association of the Pulp and Paper Industry (TAPPI standards).

\subsubsection{Content of cellulose, lignin and hemicellulose in SCB and CCS raw materials}

The lignin, cellulose and hemicellulose of the raw materials SCB and CCS were determined according to the TAPPI Standard T222 om- $88^{[27]}$, the ashes according to the norm TAPPI T211 OM $93^{[28]}$ and the extractive was 
determined according to the standard TAPPI T 204 om-88 ${ }^{[29]}$. The holocellulose content (cellulose and hemicellulose) and the pulp were determined according to standard TAPPI T13 $\mathrm{m}-54^{[30]}$, allowing the determination of the hemicellulose content. All measurements are expressed on a dry basis.

\subsubsection{Fourier transform infrared spectroscopy (FTIR)}

The FTIR spectra for the cellulose, lignin, SCB and CCS samples before and after the bleaching process were obtained on a Shimadzu IR Prestige system, performing 20 scans, with a resolution of $4 \mathrm{~cm}^{-1}$, in the range of 4000 to $600 \mathrm{~cm}^{-1}$ at room temperature. The samples were prepared in the form of compressed $\mathrm{KBr}$ disks.

\subsubsection{Thermogravimetric analysis (TGA)}

Thermal degradation measurements were taken on a Shimadzu TGA-50 thermogravimetric analyzer, from room temperature to $600{ }^{\circ} \mathrm{C}$ at a heating rate of $10{ }^{\circ} \mathrm{C} \mathrm{min}$. The flow rate of the nitrogen purge gas was $50 \mathrm{~mL} \mathrm{~min}^{-1}$.

\subsubsection{X-ray diffraction (XRD)}

$\mathrm{X}$-ray patterns of the specimens were obtained on a Philips X'Pert diffractometer (Netherlands), with $\mathrm{Cu}\left(\mathrm{K}_{\alpha}\right)$ radiation $(\lambda=1.5418 \AA)$, operating at room temperature, $30 \mathrm{~mA}$ and $40 \mathrm{kV}$. The scanned region of 2 to $40^{\circ}(2 \theta)$ and a pitch of $0.05^{\circ} \mathrm{s}^{-1}$ were applied to evaluate the crystallinity index of the SCB and CCS samples, before and after the bleaching processes. The samples were milled to yield material between 120 and 450 mesh sizes. The crystallinity index $\left(C_{\mathrm{I}}\right)$ was determined using Equation 1, by comparing the corresponding areas of the crystalline and amorphous fractions, obtained by deconvolution of the diffractogram, where $A_{A}$ is the area of the amorphous phase and $A_{\mathrm{t}}$ the total area of

$$
C_{I}=\left(1-\frac{A_{a}}{A_{t}}\right) x 100
$$

\subsection{Extraction of whiskers}

To extract the whiskers bleached fibers obtained from CCS and SCB were selected, through treatments (ii) with $\mathrm{H}_{2} \mathrm{O}_{2}$ and (iii) with $\mathrm{Ca}(\mathrm{ClO})_{2}$, as described in section 2.2. Acid hydrolysis was carried out at $55^{\circ} \mathrm{C}$ for 75 min with $60 w t \% \mathrm{H}_{2} \mathrm{SO}_{4}(1: 20 \mathrm{w} / \mathrm{v})$ under mechanical stirring. The fiber suspension was diluted with water (five times the volume of the reaction mixture) at room temperature to stop the reaction and after centrifugation the supernatant was removed. Distilled water was then added to the sediment, which was suspended under mechanical stirring, and the suspension was centrifuged until the appearance of the cloud point. This suspension of cellulose whiskers was collected and treated using dialysis bags in a cellulose acetate membrane with a cut off of $10,000 \mathrm{~g} \mathrm{~mol}^{-1}$ at neutral $\mathrm{pH}$ and stored at $5{ }^{\circ} \mathrm{C}$.

\subsection{Replacement of dispersive medium of whiskers}

The dispersive medium containing the cellulose whiskers was changed from water to DMF or DMSO, in order to solubilize the hydrophobic polymer matrix. The DMF or
DMSO was added to the aqueous suspension of cellulose whiskers and the water eliminated through vacuum distillation at $60{ }^{\circ} \mathrm{C}$, since the boiling point of a non-aqueous solvent is greater than the boiling point of water.

In the exchange of the aqueous dispersion medium containing the whiskers the volumes of solvent before and after fractional distillation were gravimetrically monitored.

\subsection{Characterization of whiskers}

\subsubsection{Whiskers in aqueous and non-aqueous media}

In order to estimate the yield of the isolation process of the whiskers and efficiency in the solvent exchange the quantity of whiskers dispersed in the aqueous and non-aqueous medium was determined using the gravimetric procedure. A sample of $2 \mathrm{~mL}$ of the whiskers suspension in aqueous medium was placed in Petri dishes and kept in an oven with air circulation at $80^{\circ} \mathrm{C}$ to evaporate the solvent. The sample was then maintained at $105^{\circ} \mathrm{C}$ until constant weight, and the quantity of whiskers was calculated and expressed as weight per volume of suspension. The yield of the hydrolysis reaction was estimated from the weight of the cellulose content of the bleached fibers. An analogous procedure was used to determine the efficiency of the solvent exchange from water to DMF or DMSO, maintaining the suspension at $130{ }^{\circ} \mathrm{C}$ until complete evaporation of the solvent.

\subsubsection{Zeta potential analysis $(\xi)$ and dynamic light scattering (DLS)}

The surface charges were measured by zeta potential analysis $(\xi)$ from an aliquot of the neutral aqueous suspension of the whiskers with the concentration equalized at $0.005 \%$ $(w / w)$. In order to evaluate the stability of the suspensions they were kept under refrigeration at $7^{\circ} \mathrm{C}$ and analyzed at 6-month intervals, after sonication (UltraCleaner 1600A) for $30 \mathrm{~min}$ and centrifugation under a force of $1370 \mathrm{x} \mathrm{g}$.

Dynamic light scattering was carried out using a Zetasizer Nano ZS system (Malvern, UK), by detecting back-scattered laser-light $\left(\theta=173^{\circ}\right)$ and comparing the coherence of scattering patterns as a function of time, with $0.002 \mathrm{~g} \mathrm{~mL}^{-1}$ of whiskers in aqueous, dimethylformamide or dimethyl sulfoxide suspensions, at $25^{\circ} \mathrm{C}$. Measurements of the particles in suspension were carried out in triplicate, and each measurement was composed of 15 runs every $10 \mathrm{~s}$. Analysis based on the diffusion rate of the particles in the fluid was conducted to calculate the autocorrelation function and deduce the particle size information.

\subsubsection{Transmission electron microscopy (TEM)}

Transmission electron microscopy analysis of the whiskers was carried out using a JEOL-1011 TEM electron microscope operating at $80 \mathrm{kV}$. One drop $\left(0.002 \mathrm{~g} \mathrm{~mL}^{-1}\right)$ of the suspension of whiskers was diluted in $2 \mathrm{~mL}$ of isopropyl alcohol and deposited on a grid coated with copper film (FORMVAR ${ }^{\circledR}$ ) and after being almost dried it was stained by adding one drop $(\sim 4 \mu \mathrm{L})$ of $3 \%$ uranyl acetate $(w / v)$. The excess liquid was removed and this was followed by drying at room temperature. 


\section{Results and Discussions}

\subsection{Characterization of raw materials}

Table 1 shows the composition of cellulose, lignin, hemicellulose, ash and extractive for the sugarcane bagasse (SCB) and corn cob straw (CCS). As expected, for both raw materials cellulose predominates in relation to the other components. The percentages of each component are consistent with values reported in the literature ${ }^{[1-6]}$. SCB fibers have a higher content of lignin and lower content of hemicellulose than CCS fibers, which affects the physiological characteristics of these fibers.

\subsection{Evaluation of the effect of bleaching process}

Figure 1 shows the FTIR spectra, in the range of $1400-1850 \mathrm{~cm}^{-1}$, for cellulose and lignin obtained by isolation from the raw materials straw corn cob straw (CCS) and sugar cane bagasse (SCB) before and after the bleaching treatments. In the range of 1400 to $1850 \mathrm{~cm}^{-1}$ the cellulose shows absorption bands at 1645 and $1430 \mathrm{~cm}^{-1}$ related to the symmetrical angular deformations of the $\mathrm{OH}$ and $\mathrm{CH}_{2}$ (constituents of the chemical structure of the cellulose repeating unit), respectively ${ }^{[31]}$. Due to the phenolic groups present in the lignin, the infrared spectrum shows absorption bands at 1600 and $1510 \mathrm{~cm}^{-1}$, related to axial deformations of the aromatic rings ${ }^{[32]}$. Besides the characteristic absorption bands of cellulose and lignin, the untreated SCB and CCS present absorption bands at $1730 \mathrm{~cm}^{-1}$, characteristic of the axial stretching of the carbonyl and associated with hemicellulose $\mathrm{e}^{[10,14]}$. The infrared spectra of the untreated SCB and CCS indicate the presence of cellulose, lignin and hemicellulose, in agreement with the results of the quantitative analysis shown in Table 1. After the alkaline treatment $(i)$ of the raw materials (SCB and CCS) there was a reduction in the intensity of the absorption bands as expected, which is associated with the functional groups present in the polymer chain of the lignin and hemicellulose. Although the $\mathrm{NaOH}$ treatment promoted the removal of lignin, the presence of shoulders at 1510 and $1600 \mathrm{~cm}^{-1}$ indicates that complete removal of lignin did not occur. In order to reduce the lignin content in the samples, we used the treatments (ii) or (iii), after which the infrared spectra suggest greater efficiency of the bleaching processes, with a reduction in the intensity of the absorption bands related to lignin.

Figure 2 shows the TG curves obtained for the pure cellulose, the lignin obtained by isolation from the raw materials, the raw material and the fibers after the bleaching processes for (a) SCB and (b) CCS. The TG curves of the raw materials exhibited similar behavior with weight loss at $100{ }^{\circ} \mathrm{C}$ associated with the removal of water molecules and in temperature range of $250{ }^{\circ} \mathrm{C}$ to $400{ }^{\circ} \mathrm{C}$ related to the thermal degradation of the constituents of the sample, while at temperatures above $400{ }^{\circ} \mathrm{C}$ only the solid waste residue remained. The residue of the lignin isolated from SCB and CCS is higher than the residue of cellulose and other studied samples. At $450{ }^{\circ} \mathrm{C}$ there was $23 \%$ of residue for the raw material samples and $63 \%$ and $71 \%$ of residue for lignin from SCB and CCS, respectively. The percentages of residue for the fibers after treatment with hydrogen peroxide were $19 \%$ and $13 \%$ for SCB and CCS, respectively. These values of residue percentage is related to higher quantity of lignin in SCB than in CCS samples after bleaching

Table 1. Composition mass percentage of sugarcane bagasse (SCB) and corn cob straw (CCS).

\begin{tabular}{cccccc}
\hline Raw material & Cellulose & Lignin & Hemicellulose & Ash & $2.8 \pm 0.3$ \\
SCB & $44.6 \pm 1.2$ & $24.0 \pm 1.3$ & $26.0 \pm 2.1$ & $2.5 \pm 0.3$ & $1.5 \pm 0.1$ \\
CCS & $47.3 \pm 2.1$ & $14.4 \pm 0.9$ & $34.8 \pm 2.3$ & $2.0 \pm 0.2$ \\
\hline
\end{tabular}
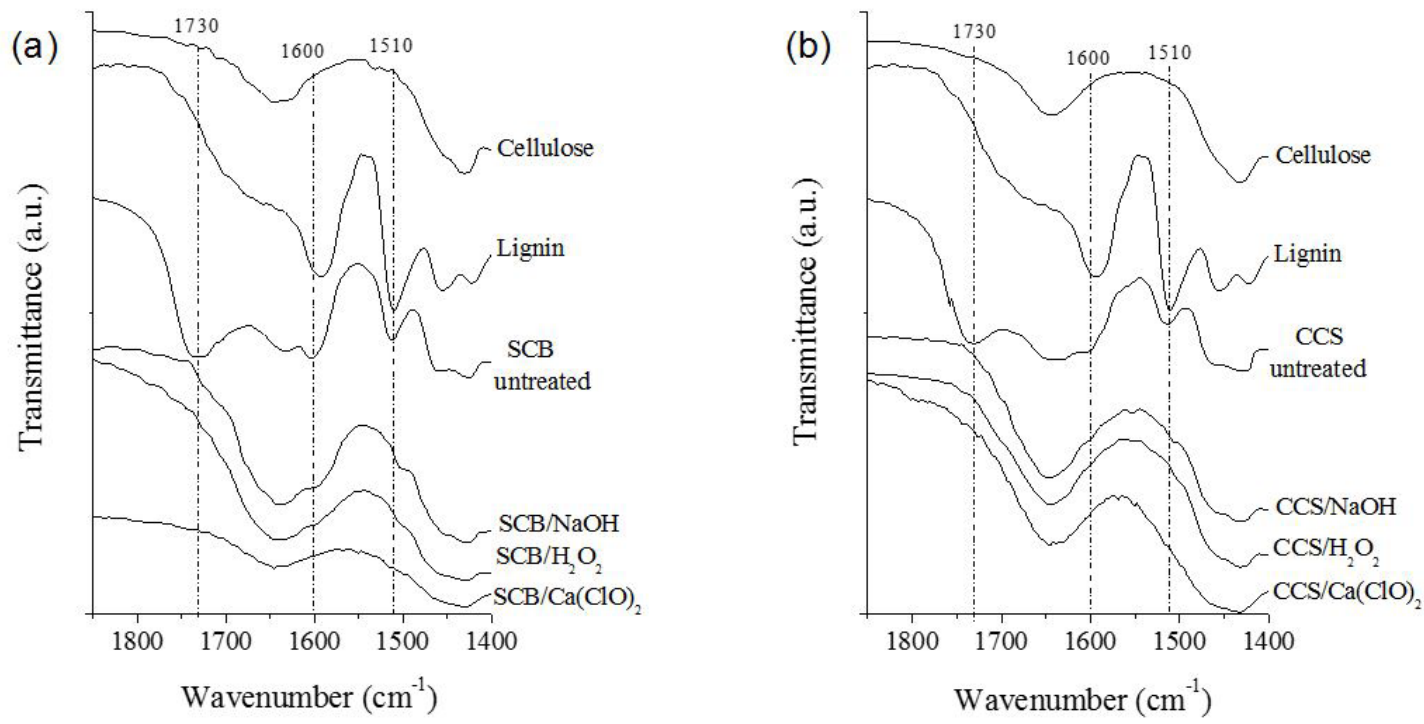

Figure 1. Infrared spectra for pure cellulose, lignin and the samples after the bleaching process (indicated in the figure) using (a) SCB and (b) CCS as raw materials. 

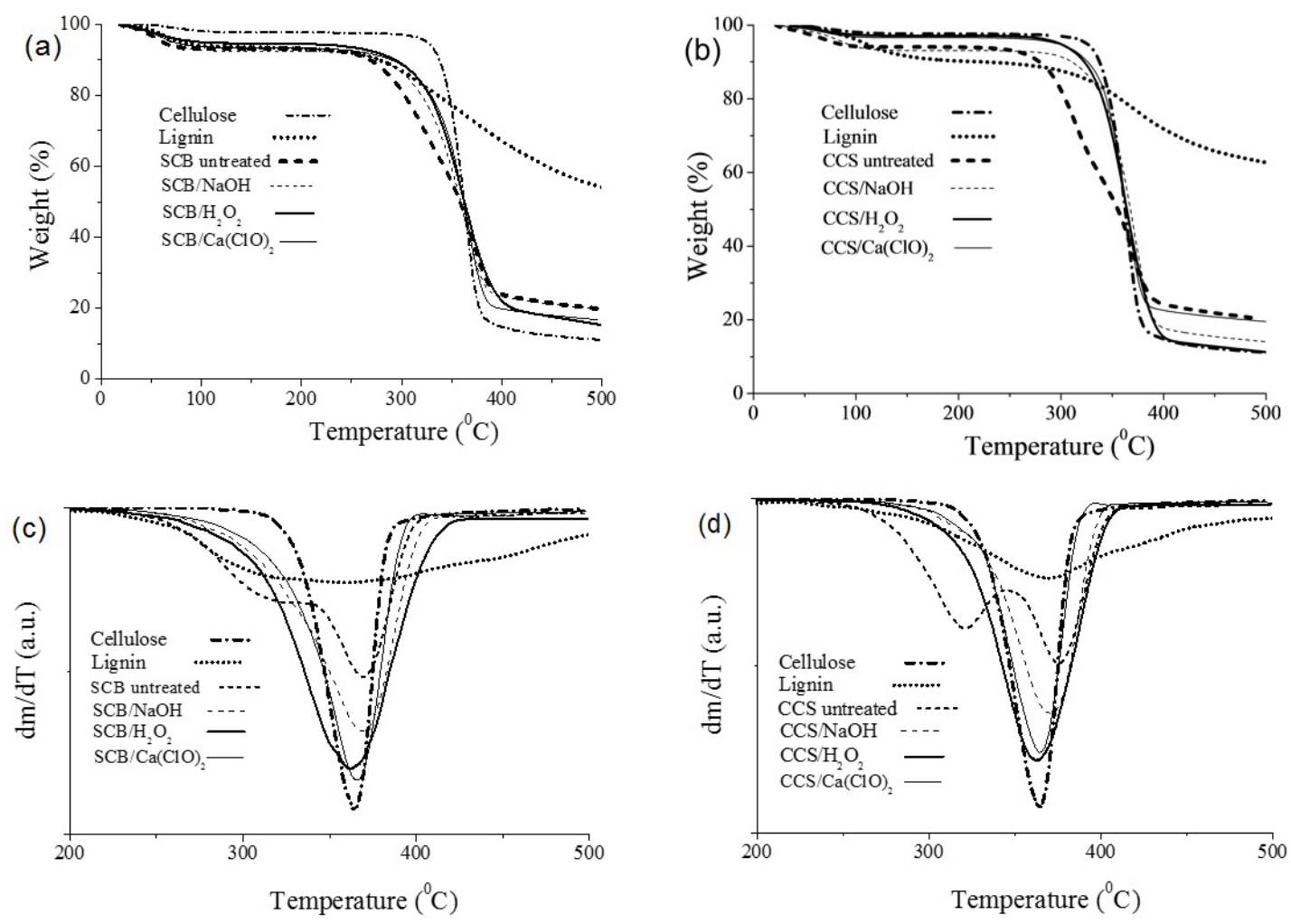

Figure 2. TG curves and DTG curves for (a, c) SCB and (b, d) CCS related to pure cellulose, lignin and the samples after the bleaching processes (indicated in the figure).

processes, as can be seen by relative intensity at $1510 \mathrm{~cm}^{-1}$ and $1600 \mathrm{~cm}^{-1}$ in the FTIR spectra, since the lignin was not totally removed. The amount of residue observed after the calcium hypochlorite process can be included the presence of calcium compound.

The DTG curves enable the visualization of the different stages of thermal degradation of the components in the samples, as shown in Figure 2c, $d$ for samples derived from SCB and CCS, respectively.

Pure cellulose presents a single-stage thermal degradation event with the maximum degradation rate at $365^{\circ} \mathrm{C}$, as described in the literature ${ }^{[10,33]}$. Besides the degradation stage associated with cellulose, the raw materials presented other degradation stages related to lignocellulosic material, such as lignin and hemicellulose ${ }^{[33]}$. After treatment $(i)$ with $\mathrm{NaOH}$, the behavior of the DTG curve with a single stage of thermal degradation tends to be similar to that of pure cellulose, indicating the removal of the lignocellulosic components. This tendency was noted for the sequence of treatments with hydrogen peroxide and calcium hypochlorite, indicating greater efficiency for these bleaching processes. This behavior was observed for CCS and SCB, in agreement with the residue levels observed in the thermal analysis and infrared spectroscopy.

Figure 3a, b show the diffractograms for the SCB and CCS raw materials after treatments (ii) and (iii), respectively, with peaks at $14.7^{\circ}, 16.6^{\circ}, 22.5^{\circ}$ and $34.7^{\circ}$, which relate to the families of crystalline planes: (101), (10 $\overline{1}),(002)$ and (004), respectively, characteristic of the cellulose $I^{[34]}$. The peaks associated with the crystal structure suggest that the alkali treatment is not aggressive in relation to changes in the cellulose crystal lattice. According to Borysiak and Doczekalska $^{[35]}$, the crystalline structure of cellulose can change from cellulose I to cellulose II in an aqueous 15\% $\mathrm{NaOH}(w / v)$ solution.

The crystallinity index was $30 \%$ for both of the raw materials studied. After the bleaching process the fibers obtained from SCB showed values for the crystallinity index of $70 \%$ and $68 \%$, after treatment with hydrogen peroxide and calcium hypochlorite, respectively. For the fibers obtained from CCS the crystallinity index was $67 \%$ after both treatments. For comparison, the crystallinity index determined by Rosa et al. ${ }^{[12]}$ for rice husk cellulose and microcrystalline cellulose were $67 \%$ and $79 \%$, respectively. An increase in the $C_{\mathrm{I}}$ values indicates a greater quantity of crystalline cellulose in the samples compared to amorphous material, which is related to the effectiveness in the removal of hemicelluloses and lignin, in agreement with the results obtained in the infrared spectroscopy and thermogravimetric analysis.

\subsection{Characterization of whiskers}

Table 2 shows the yields for the whiskers isolated from the bleached raw materials by acid hydrolysis. A value of $60 \%$ $(w / w)$ was obtained for the bleached cellulose, suggesting that the process used for the isolation of the nanocrystals 

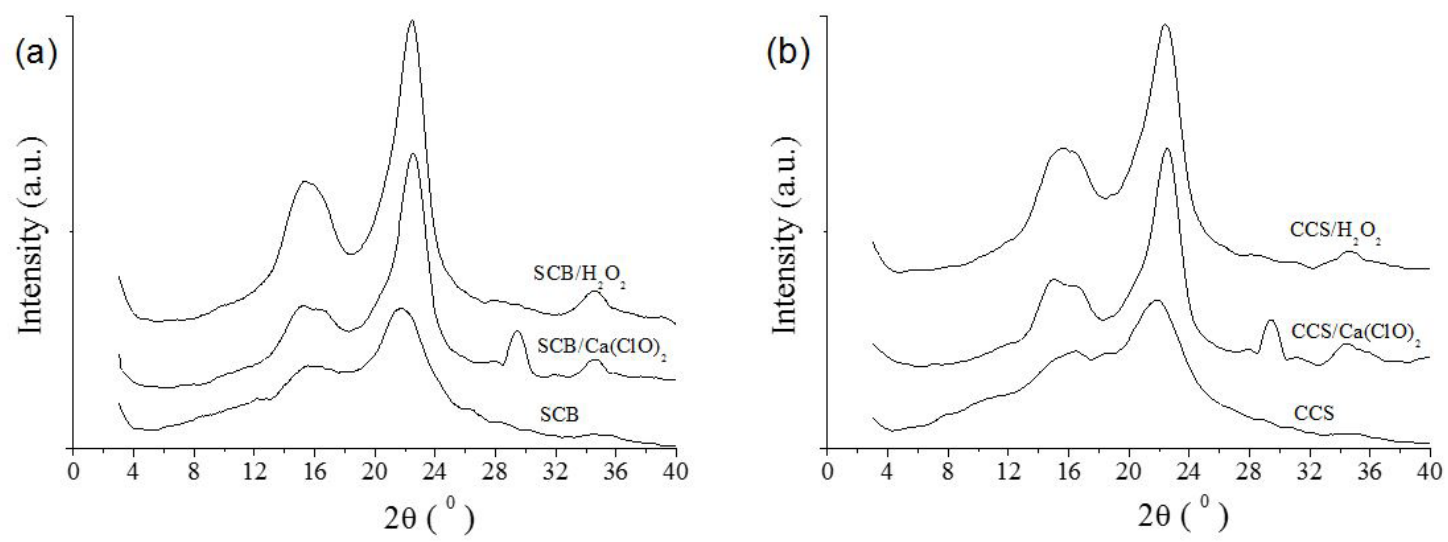

Figure 3. XRD spectra for (a) $\mathrm{SCB}$ and (b) $\mathrm{CCS}$ raw materials and after treatments with $\mathrm{H}_{2} \mathrm{O}_{2} / \mathrm{NaOH}$ or $\mathrm{Ca}(\mathrm{ClO})_{2} / \mathrm{NaOH}$ (as indicated in the figure).

had a good efficiency, regardless of the bleaching process and raw material used. The literature reports different yields for the whiskers according to the hydrolysis conditions applied for the bleaching of the fibers. Correa ${ }^{[36]}$ studied the hydrolysis of curauá fibers with $60 \% \mathrm{H}_{2} \mathrm{SO}_{4}(v / v)$ at $45^{\circ} \mathrm{C}$ for $75 \mathrm{~min}$ and obtained a whiskers yield of $70 \%$ while Taipina ${ }^{[37]}$ using the same kind of fiber obtained a yield of $65 \%$. On the other hand, Oksman and Bondeson et al. ${ }^{[38]}$ carried out hydrolysis with $\mathrm{H}_{2} \mathrm{SO}_{4}(63.5 \%$ w/w) , using a 10:1 $(v / w)$ solution/raw material ratio and a reaction time of $2 \mathrm{~h}$ and obtained whiskers with a yield of $30 \%$. Dong et al. ${ }^{[39]}$ reported yields of between $35 \%$ and $48 \%$ when varying the hydrolysis conditions $\left(64 \% \mathrm{H}_{2} \mathrm{SO}_{4} w / w\right)$ applying temperatures of $26{ }^{\circ} \mathrm{C}$ to $65{ }^{\circ} \mathrm{C}$ and reaction times of between $0.25 \mathrm{~h}$ and $18 \mathrm{~h}$. Mathew et al. ${ }^{[40]}$ studied wood waste from the production of ethanol, after bleaching and acid hydrolysis and recorded $46 \%$ yield for the whiskers. In this regard, we also conducted preliminary experiments under more severe conditions, with $65 \% \mathrm{H}_{2} \mathrm{SO}_{4}(w / w)$, a temperature of 55 ${ }^{\circ} \mathrm{C}$ and 75 min of reaction and with $60 \% \mathrm{H}_{2} \mathrm{SO}_{4}(w / w)$ at $55^{\circ} \mathrm{C}$ for $300 \mathrm{~min}$, and in both cases the yield of whiskers obtained was $30 \%$. However, the suspensions had a dark color, indicating the carbonization of the whiskers.

The stability of aqueous suspensions of whiskers was analyzed via the zeta potential $(\xi)$. The values obtained at 6-month intervals are shown in Table 3. The potential of around $-64 \mathrm{mV}$ in neutral aqueous medium $(\mathrm{pH}$ between 6.0 and 7.0) is indicative of negative charges on the surface of the whiskers, due to the grafting of sulfate groups in the cellulose hydrolysis process ${ }^{[41,42]}$. These groups enable the formation of a colloidal suspension and its stability is due to the electrostatic repulsion of these surface charges ${ }^{[40]}$. According to Greenwood ${ }^{[43]}$, potentials above $30 \mathrm{mV}$ are sufficient for obtaining a suspension with good stability.

The morphology and size of the whiskers were evaluated by transmission electron microscopy (TEM) and dynamic light scattering (DLS). Figure 4a, b show the TEM micrographs for the whiskers dispersed in water. For both raw materials (SCB and CCS) the whiskers were rod shaped (acicular), which is characteristic of structural rigidity. For SCB the average length $(L)$ was $230 \pm 35 \mathrm{~nm}$ and the average diameter $(D)$ determined by TEM was $16 \pm 3 \mathrm{~nm}$, with an
Table 2. Yields obtained for the whiskers after the hydrolysis processes.

\begin{tabular}{ccc}
\hline Raw material & Bleaching process & Yield (\%) \\
\hline \multirow{2}{*}{$\mathrm{SCB}$} & $\mathrm{SCB} / \mathrm{H}_{2} \mathrm{O}$ & 60 \\
& $\mathrm{SCB} / \mathrm{Ca}(\mathrm{ClO})_{2}$ & 55 \\
\hline \multirow{2}{*}{$\mathrm{CCS}$} & $\mathrm{CCS} / \mathrm{H}_{2} \mathrm{O}_{2}$ & 65 \\
& $\mathrm{CCS} / \mathrm{Ca}(\mathrm{ClO})_{2}$ & 60 \\
\hline
\end{tabular}

Table 3. Zeta potential (mV) of whiskers

\begin{tabular}{ccc}
\hline $\begin{array}{c}\text { Storage time } \\
\text { (months) }\end{array}$ & SCB & CCS \\
\hline 0 & $-64.3 \pm 6.9$ & $-65.2 \pm 7.8$ \\
6 & $-64.1 \pm 1.5$ & $-64.1 \pm 0.7$ \\
12 & $-63.2 \pm 1.2$ & $-65.6 \pm 4.5$ \\
\hline
\end{tabular}

aspect ratio $(L / D)$ of 15 . For the CCS the values determined by TEM were $L=288 \pm 62 \mathrm{~nm}$ and $D=16 \pm 4 \mathrm{~nm}$, with an $L / D$ ratio of 18 . The acicular shape and dimensions are similar to those described in the literature for whiskers, with lengths of around 35 to $500 \mathrm{~nm}$ and diameters of between 3 and $15 \mathrm{~nm}^{[7,15]}$. More specifically, for sugarcane bagasse, Teixeira et al. ${ }^{[1]}$ obtained average values for the length and diameter of $255 \pm 55 \mathrm{~nm}$ and $8 \pm 3 \mathrm{~nm}$, respectively, while Mandal et al. ${ }^{[10]}$ reported a shorter length $(170 \mathrm{~nm})$ and larger diameter $(35 \mathrm{~nm})$.

Lima et al.${ }^{[4]}$ and Braun et al ${ }^{[45]}$ considered the Broersma relationships using the rotation and translational diffusion coefficients to obtain the dimensions of the whiskers. According to these authors, the spheroidal form factor contains more than one adjustable parameter, allowing the simultaneous determination of the diameter and length, which are related to the size of the whiskers. Thus, using the DLS technique the values obtained for the dimensions of the whiskers were $232 \pm 5 \mathrm{~nm}$ and $242 \pm 15 \mathrm{~nm}$ for SCB and CCS, respectively, which are in agreement with the values determined by TEM.

On the other hand, for the whiskers obtained from SCB under more severe hydrolysis conditions, with $65 \% \mathrm{H}_{2} \mathrm{SO}_{4}$ (w/w) at $55{ }^{\circ} \mathrm{C}$ for $75 \mathrm{~min}$, the size obtained by DLS was $167 \pm 2 \mathrm{~nm}$, which indicates that the hydrolysis conditions 
can alter ${ }^{[39]}$ the dimensions and surface characteristics of the whiskers, as well as their yield. Thus, it is possible to control the aspect ratio $(L / D)$ and surface area, which are important characteristics of nanocrystals, making them of interest for different applications.

The incorporation of whiskers, homogeneously distributed in matrices of water-insoluble polymers presents a great challenge. Approaches commonly applied to overcome this difficulty include the use of surfactants, the surface functionalization of the whiskers and/or the lyophilization and solvent dispersion of hydrophobic polymer matrices. However, a large quantity of surfactants is required to maintain the stability of the suspension due to the high specific surface area of the nanocrystals. Furthermore, as observed by Bondeson and Oksman ${ }^{[21]}$ the surfactants may cause degradation of the polymer matrix. On the other hand, Peterson et al. ${ }^{[19]}$ reports that when lyophilizing a suspension of whiskers in aqueous medium and after their dispersion in chloroform, undesirable flakes are formed in the solvent. Viet et al. ${ }^{[46]}$ studied a suspension of lyophilized whiskers in aqueous medium and their subsequent dispersion in dimethylformamide and dimethyl sulfoxide, while maintaining the aggregates in the suspension. Kamal et al. ${ }^{[47]}$ used the spray dried, freeze drying and spray freeze drying of whiskers while maintaining agglomerates in suspension in molten polymer (PLA) at a minimum size of $1 \mu \mathrm{m}$.

In this study, we replaced the aqueous dispersion medium with dimethylformamide or dimethyl sulfoxide, as described in the experimental section, and evaluated the morphology and dispersion characteristics of the whiskers in these non-aqueous media.

Figure 5a, b show the TEM micrographs of the whiskers obtained from SCB and CCS as raw materials, respectively, dispersed in dimethylformamide. A homogenous dispersion of the whiskers was maintained, and the lengths $(L)$ were $240 \pm 61 \mathrm{~nm}$ and $245 \pm 80 \mathrm{~nm}$ and the diameters $(D)$ were $16 \pm 5 \mathrm{~nm}$ and $18 \pm 6 \mathrm{~nm}$ for SCB and the CCS, respectively. These dimensions are in agreement with the values obtained through DLS of $240( \pm 26)$ for SCB and $250( \pm 8)$ for CCS in dimethylformamide and $224( \pm 5)$ for SCB and $244( \pm 8)$ for CCS in dimethyl sulfoxide.

The solvent exchange procedure was effective and appropriate to maintain the dispersion of the whiskers. As discussed above, the method is simple and inexpensive, indicating that the solvent mixture is not azeotropic and since there was a considerable difference between the boiling temperatures of the solvents efficient water removal could be carried out by fractional distillation.
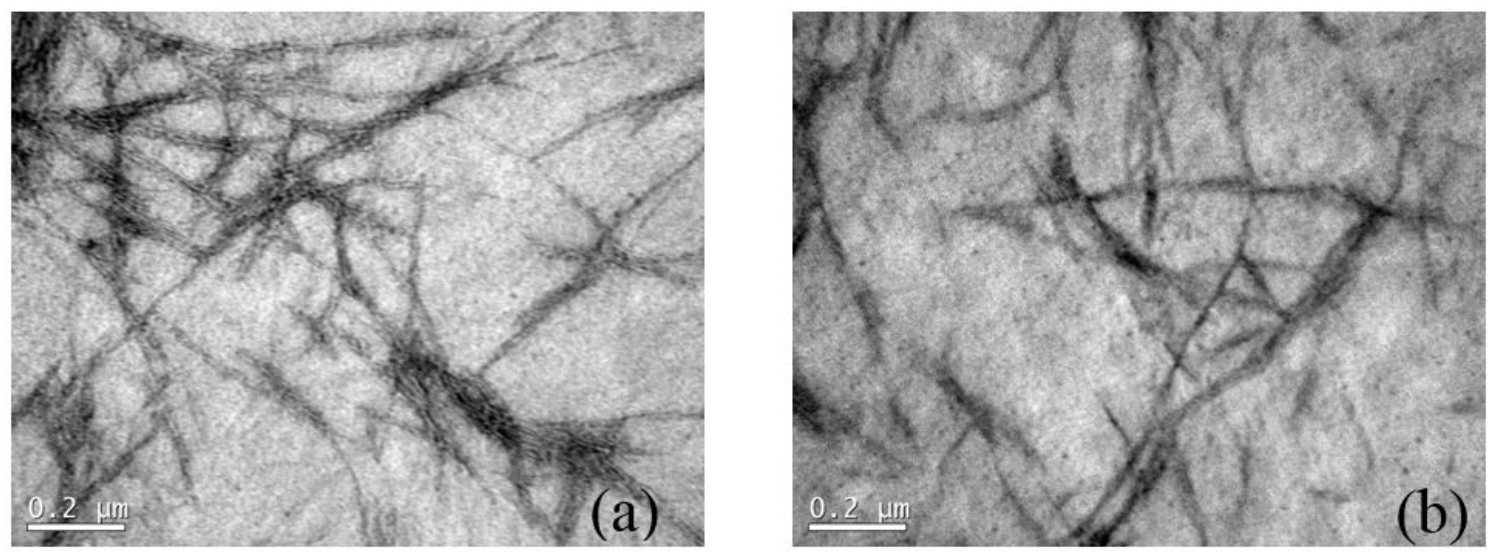

Figure 4. TEM micrographs for whiskers dispersed in aqueous medium obtained from (a) SCB and (b) CCS as raw materials.
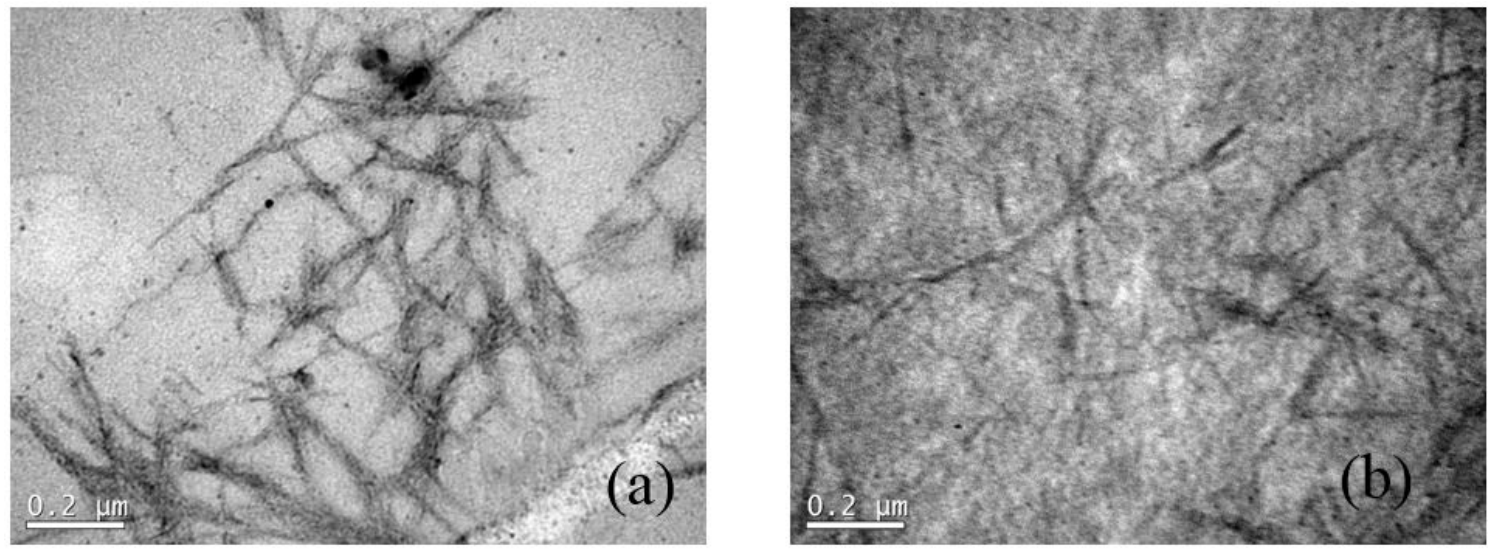

Figure 5. TEM micrographs for whiskers obtained from (a) SCB and (b) CCS as raw materials dispersed in DMF. 


\section{Conclusions}

The procedures used for the isolation of whiskers and the oxidant/alkali bleaching processes followed by acid hydrolysis were found to be effective, providing good yields and dimensional characteristics as well as dispersity in a solvent medium. The isolated whiskers had nanometric dimensions and aspect ratio $(L / D)$ values comparable with those reported in the literature. When the aqueous medium was replaced with a non-aqueous medium using a simple low cost technique, without the need for mechanical work, the whiskers remained dispersed and the morphological characteristics of the whiskers were maintained. The dispersion of the whiskers in a non-aqueous solvent facilitates future studies on the development of techniques to obtain nanocomposite whiskers homogeneously dispersed in matrices of polymers by dissolving them in a common solvent followed by solvent evaporation.

\section{Acknowledgements}

The authors are grateful for the financial support provided by CAPES and CNPq and also for the characterization by Transmission Electron Microscopy performed by LCME - UFSC.

\section{References}

1. Teixeira, E. de M., Bondancia, T. J., Teodoro, K. B. R., Corrêa, A. C., Marconcini, J. M., \& Mattoso, L. H. C. (2011). Sugarcane bagasse whiskers: extraction and characterizations. Industrial Crops and Products, 33(1), 63-66. http://dx.doi.org/10.1016/j. indcrop.2010.08.009.

2. Vallejos, M. E., Felissia, F. E., Kruyeniski, J., \& Area, M. C. (2015). Kinetic study of the extraction of hemicellulosic carbohydrates from sugarcane bagasse by hot water treatment. Industrial Crops and Products, 67, 1-6. http://dx.doi.org/10.1016/j. indcrop.2014.12.058.

3. Rocha, G. J. de M., Nascimento, V. M., Gonçalves, A. R., Silva, V. F. N., \& Martín, C. (2015). Influence of mixed sugarcane bagasse samples evaluated by elemental and physical-chemical composition. Industrial Crops and Products, 64, 52-58. http:// dx.doi.org/10.1016/j.indcrop.2014.11.003.

4. Dermibás, A. (2003). Relationships between lignin contents and fixed carbon contents of biomass samples. Energy Conversion and Management, 44(9), 1481-1486. http://dx.doi.org/10.1016/ S0196-8904(02)00168-1.

5. Fu, S.-F., Wang, F., Yuan, X.-Z., Yang, Z.-M., Luo, S.-J., Wang, C.-S., \& Guo, R.-B. (2015). The thermophilic $\left(55^{\circ} \mathrm{C}\right)$ microaerobic pretreatment of corn straw for anaerobic digestion. Bioresource Technology, 175, 203-208. PMid:25459823. http:// dx.doi.org/10.1016/j.biortech.2014.10.072.

6. Chundawat, S. P. S., Venkatesh, B., \& Dale, B. E. (2007). Effect of particle size based separation of milled corn stover on AFEX pretreatment and enzymatic digestibility. Biotechnology and Bioengineering, 96(2), 219-231. PMid:16903002. http:/ dx.doi.org/10.1002/bit.21132.

7. Habibi, Y., Lucia, L. A., \& Rojas, O. J. (2010). Cellulose nanocrystals: chemistry, self-assembly, and applications. Chemical Reviews, 110(6), 3479-3500. PMid:20201500. http:// dx.doi.org/10.1021/cr900339w.

8. Oksman, K., Mathew, A. P., Bondeson, D., \& Kvien, I. (2006). Manufacturing process of cellulose whiskers/polylactic acid nanocomposites. Composites Science and Technology, 66(15), 2776-2784. http://dx.doi.org/10.1016/j.compscitech.2006.03.002.
9. Lee, Y.-J., Chung, C.-H., \& Day, D. F. (2009). Sugarcane bagasse oxidation using a combination of hypochlorite and peroxide. Bioresource Technology, 100(2), 935-941. PMid:18693013. http://dx.doi.org/10.1016/j.biortech.2008.06.043.

10. Mandal, A., \& Chakrabarty, D. (2011). Isolation of nanocellulose from waste sugarcane bagasse (SCB) and its characterization. Carbohydrate Polymers, 86(3), 1291-1299. http://dx.doi. org/10.1016/j.carbpol.2011.06.030.

11. Sun, J. X., Sun, X. F., Zhao, H., \& Sun, R. C. (2004). Isolation and characterization of cellulose from sugarcane bagasse. Polymer Degradation \& Stability, 84(2), 331-339. http://dx.doi. org/10.1016/j.polymdegradstab.2004.02.008.

12. Rosa, S. M. L., Rehman, N., Miranda, M. I. G., Nachtigall, S. M. B., \& Bica, C. I. D. (2012). Chlorine-free extraction of cellulose from rice husk and whisker isolation. Carbohydrate Polymers, 87(2), 1131-1138. http://dx.doi.org/10.1016/j. carbpol.2011.08.084.

13. Zhao, X.-B., Wang, L., \& Liu, D.-H. (2008). Peracetic acid pretreatment of sugarcane bagasse for enzymatic hydrolysis: a continued work. Journal of Chemical Technology and Biotechnology (Oxford, Oxfordshire), 83(6), 950-956. http:// dx.doi.org/10.1002/jctb.1889.

14. Ramadoss, G., \& Muthukumar, K. (2015). Influence of dual salt on the pretreatment of sugarcane bagasse with hydrogen peroxide for bioethanol production. Chemical Engineering Journal, 260, 178-187. http://dx.doi.org/10.1016/j.cej.2014.08.006.

15. Moon, R. J., Martini, A., Nairn, J., Simonsen, J., \& Youngblood, J. (2011). Cellulose nanomaterials review: structure, properties and nanocomposites. Chemical Society Reviews, 40(7), 39413994. PMid:21566801. http://dx.doi.org/10.1039/c0cs00108b.

16. Rhim, J.-W., Park, H.-M., \& Ha, C.-S. (2013). Bio-nanocomposites for food packaging applications. Progress in Polymer Science, 38(10-11), 1629-1652. http://dx.doi.org/10.1016/j. progpolymsci.2013.05.008.

17. Reddy, M. M., Vivekanandhan, S., Misra, M., Bhatia, S. K., \& Mohanty, A. K. (2013). Biobased plastics and bionanocomposites: Current status and future opportunities. Progress in Polymer Science, 38(10-11), 1653-1689. http://dx.doi.org/10.1016/j. progpolymsci.2013.05.006.

18. Samir, M. A. S. A., Alloin, F., Sanchez, J.-Y., \& Dufresne, A. (2005). Nanocomposite polymer electrolytes based on poly(oxyethylene) and cellulose whiskers. Polimeros: Ciência e Tecnologia, 15(2), 109-113. http://dx.doi.org/10.1590/S010414282005000200009 .

19. Petersson, L., Kvien, I., \& Oksman, K. (2007). Structure and thermal properties of poly(lactic acid)/cellulose whiskers nanocomposite materials. Composites Science and Technology, 67(11-12), 2535-2544. http://dx.doi.org/10.1016/j. compscitech.2006.12.012.

20. Kaboorani, A., \& Riedl, B. (2015). Surface modification of cellulose nanocrystals $(\mathrm{CNC})$ by a cationic surfactant. Industrial Crops and Products, 65, 45-55. http://dx.doi.org/10.1016/j. indcrop.2014.11.027.

21. Bondeson, D., \& Oksman, K. (2007). Polylactic acid/cellulose whisker nanocomposites modified by polyvinyl alcohol. Composites. Part A, Applied Science and Manufacturing, 38(12), 2486-2492. http://dx.doi.org/10.1016/j.compositesa.2007.08.001.

22. Araki, J., Wada, M., \& Kuga, S. (2001). Steric stabilization of a cellulose microcrystal suspension by poly(ethylene glycol) grafting. Langmuir, 17(1), 21-27. http://dx.doi.org/10.1021/ la001070m

23. Fortunati, E., Peltzer, M., Armentano, I., Torre, L., Jiménez, A., \& Kenny, J. M. (2012). Effects of modified cellulose nanocrystals on the barrier and migration properties of PLA nano-biocomposites. Carbohydrate Polymers, 90(2), 948-956. PMid:22840025. http://dx.doi.org/10.1016/j.carbpol.2012.06.025. 
24. Dufresne, A., \& Belgacem, M. N. (2013). Cellulose-reinforced composites: from micro-to nanoscale. Polímeros: Ciência e Tecnologia, 23(3), 277-286. http://dx.doi.org/10.4322/ polimeros.2010.01.001.

25. Yu, H.-Y., Qin, Z.-Y., Liu, Y.-N., Chen, L., Liu, N., \& Zhou, Z. (2012). Simultaneous improvement of mechanical properties and thermal stability of bacterial polyester by cellulose nanocrystals. Carbohydrate Polymers, 89(3), 971-978. PMid:24750888. http://dx.doi.org/10.1016/j.carbpol.2012.04.053.

26. Pracella, M., Haque, M. M. U., \& Puglia, D. (2014). Morphology and properties tuning of PLA/cellulose nanocrystals bionanocomposites by means of reactive functionalization and blending with PVAc. Polymer, 55(16), 3720-3728. http:// dx.doi.org/10.1016/j.polymer.2014.06.071.

27. Technical Association of the Pulp and Paper Industry - TAPPI. (1999). Method T222 om-88. Peachtree Corners: TAPPI.

28. Technical Association of the Pulp and Paper Industry - TAPPI. (1993). Method T211 om-93. Peachtree Corners: TAPPI.

29. Technical Association of the Pulp and Paper Industry - TAPPI (1989). Method T204 om-88. Peachtree Corners: TAPPI.

30. Technical Association of the Pulp and Paper Industry - TAPPI (1991). Method T19m-54. Peachtree Corners: TAPPI.

31. Baldinger, T., Moosbauer, J., \& Sixta, H. (2000). Supermolecular structure of cellulosic materials by Fourier Transform Infrared Spectroscopy (FT-IR) calibrated by WAXS and 13C NMR. Lenzing Berichte, 79, 15-17.

32. Rumyantseva, Y. I., Zhbankov, R. G., Marhevka, R., \& Rataiczakb, H. (1994). IR spectra and structure of alkaline lignin and thiolignin. Journal of Applied Spectroscopy, 61, 5-6.

33. Wang, G., Li, W., Li, B., \& Chen, H. (2008). TG study on pyrolysis of biomass and its three components under syngas. Fuel, 87(4-5), 552-558. http://dx.doi.org/10.1016/j. fuel.2007.02.032

34. Ford, E. N. J., Mendon, S. K., Thames, S. F., \& Rawlins, J. W. (2010). X-ray Diffraction of cotton treated with neutralized vegetable oil-based macromolecular crosslinkers. Journal of Engineered Fibers and Fabrics, 5(1), 10-20.

35. Borysiak, S., \& Doczekalska, B. (2005). "X-ray diffraction study of pine wood treated with $\mathrm{NaOH}$. Fibres \& Textiles in Eastern Europe, 13(53), 87-89.

36. Correa, A. C. (2010). Preparação de nanofibras de celulose a partir de fibras de curauá para desenvolvimento de nanocompósitos poliméricos com EVA (Doctoral thesis). Universidade Federal de São Carlos, São Carlos.

37. Taipina, M. O. (2012). Nanocristais de celulose: obtenção, caracterização e modificação de superficie (Master's dissertation). Universidade Estadual de Campinas, Campinas.

38. Bondeson, D., Mathew, A., \& Oksman, K. (2006). Optimization of the isolation of nanocrystals from microcristalline cellulose by acid hydrolysis. Cellulose, 13, 171. http:// doi:10.1016/j. compositesa.2007.08.001.

39. Dong, X. M., Revol, J.-F., \& Gray, D. G. (1998). Effect of microcrystallite preparation conditions on the formation of colloid crystals of cellulose. Cellulose (London, England), 5(1), 19-32. http://dx.doi.org/10.1023/A:1009260511939.

40. Mathew, A. P., Oksman, K., Karim, Z., Liu, P., Khan, S. A., \& Naseri, N. (2014). Process scale up and characterization of wood cellulose nanocrystals hydrolysed using bioethanol pilot plant. Industrial Crops and Products, 58, 212-219. http:// dx.doi.org/10.1016/j.indcrop.2014.04.035.

41. Teixeira, E. M., Oliveira, C. R., Mattoso, L. H. C., Corrêa, A. C., \& Paladin, P. D. (2010). Nanofibras de algodão obtidas sob diferentes condições de hidrólise ácida. Polímeros: Ciência e Tecnologia, 20(4), 264-268. http://dx.doi.org/10.1590/S010414282010005000046 .

42. Teodoro, K. B. R., Teixeira, E. M., Corrêa, A. C., de Campos, A., Marconcini, J. M., \& Mattoso, L. H. C. (2011). Whiskers de fibra de sisal obtidos sob diferentes condições de hidrólise ácida: efeito do tempo e da temperatura de extração. Polímeros: Ciência e Tecnologia, 21(4), 280-285. http://dx.doi.org/10.1590/ S0104-14282011005000048.

43. Greenwood, R. (2003). Review of the measurement of zeta potentials in concentrated aqueous suspensions using electroacoustics. Advances in Colloid and Interface Science, 106(1-3), 55-81. PMid:14672842. http://dx.doi.org/10.1016/ S0001-8686(03)00105-2.

44. Lima, M. M. S., Wong, J. T., Paillet, M., Borsali, R., \& Pecora, R. (2003). Translational and rotational dynamics of rodlike cellulose whiskers. Langmuir, 19(1), 24-29. http://dx.doi. org/10.1021/la020475z

45. Braun, B., Dorgan, J. R., \& Chandler, J. P. (2008). Cellulosic nanowhiskers: theory and application of light scattering from polydisperse spheroids in the rayleigh-gans-debye regime. Biomacromolecules, 9(4), 1255-1263. PMid:18357993. http:// dx.doi.org/10.1021/bm7013137.

46. Viet, D., Beck-Candanedo, S., \& Gray, D. G. (2007). Dispersion of cellulose nanocrystals in polar organic solvents. Cellulose (London, England), 14(2), 109-113. http://dx.doi.org/10.1007/ s10570-006-9093-9.

47. Kamal, M. R., \& Khoshkava, V. (2015). Effect of cellulose nanocrystals $(\mathrm{CNC})$ on rheological and mechanical properties and crystallization behavior of PLA/CNC nanocomposites. Carbohydrate Polymers, 123, 105-114. PMid:25843840. http:/ dx.doi.org/10.1016/j.carbpol.2015.01.012.

Received: Nov. 09, 2015

Revised: Feb. 07, 2016

Accepted: Mar. 21, 2016 